\title{
Responsibility and the Problem of So-Called Marginal Agents
}

\begin{abstract}
:
Philosophical views of responsibility often identify responsible agency with capacities like rationality and self-control. Yet in ordinary life, we frequently hold individuals responsible who are deficient in these capacities, such as children or people with mental illness. The existing literature that addresses these cases has suggested that we merely pretend to hold these agents responsible, or that they are responsible to a diminished degree. In this paper, I demonstrate that neither of these approaches is satisfactory, and offer an alternative focused on the role relationships play in determining whether it is appropriate to hold someone responsible. I argue that relationships are sources of normative expectations about how parties in that relationship ought to behave, and that we can be responsible in virtue of being subject to these norms. This is so, not only for those who are impaired or immature, but for all of us.
\end{abstract}

Keywords: responsibility, marginal agency, relationships, norms

\section{Introduction}

Much of the existing philosophical literature about responsibility begins by asking what it takes for an agent to be responsible. This line of inquiry then frequently proceeds by considering what capacities might distinguish paradigm responsible agents (i.e., psychologically normal adult human beings) from lower animals, inanimate objects, and human beings who are not responsible agents par excellence. Possible candidates for such capacities include rationality, self-control, and the capacity to deliberate before acting.

In addition to the interest philosophers have had in giving accounts of the capacities that underwrite responsible agency, there has been increasing interest in our social practices of holding people responsible. There has not been sufficient investigation, however, of how those practices involve agents who are impaired or immature, and therefore deficient in the capacities typically regarded as necessary for being responsible. ${ }^{1}$ Yet in ordinary life, we hold individuals who are

Thanks to Joshua Blanchard, Owen Flanagan, Jonathan Knutzen, Alycia LaGuardia-LoBianco, Doug MacLean, Ram Neta, and especially Susan Wolf for helpful comments on earlier drafts of this paper. I am also grateful to audiences at University of Pennsylvania and the McCoy Family Center for Ethics in Society, as well as to the editors and an anonymous reviewer for this journal. 
deficient in these capacities responsible all the time; this is a vital part of, for example, parenting and psychotherapy. Careful attention to these undertheorized contexts shows us that to be responsible for anything is always to be responsible to someone for something, or so I will argue here.

\section{The Contours of Our Practice}

In this paper, I will consider a range of cases of holding people responsible that has been underexplored in the existing literature: cases involving so-called "marginal agents" such as young children, people with cognitive disabilities, and people with psychiatric disorders. ${ }^{2}$ What I will say about these cases leaves open the question of just how responsible these agents are according to theories that identify responsibility with the rational and volitional capacities described above. My discussion is motivated instead by the observation that in some important ways, these individuals are undoubtedly participants in at least some of our responsibility practices. A parent who chose not to hold his daughter responsible for anything merely because she was a child, for example, would be misguided at best; this would be similarly true of a therapist who chose not to hold her patients

\footnotetext{
${ }^{1}$ There is a substantial literature on the question of whether an agent's being responsible is metaphysically more basic than her being held responsible. For a range of views on this topic, see Brink and Nelkin (2013), Smith (2007), Wallace (1994), Watson (2004), Shoemaker (2017) and McKenna (2012). This priority question is independent of what I am claiming here: that is, that holding impaired or immature agents (i.e., "marginal agents") responsible is a legitimate and commonplace part of our responsibility practices that remains undertheorized. Moreover, I contend that correctly describing this practice has important consequences for what it means not only to hold someone responsible, but to be responsible in our social world. I share Strawson's methodological commitment to seeing the social practices of responsibility as fundamental, and theories of responsibility as beholden to those practices. I also share his wariness of overintellectualizing our discussions of responsibility, and thinking that any claim about the nature of responsibility must be understood in metaphysical terms.
}

${ }^{2}$ I would prefer not to use the term "marginal agents" because I view it as an underestimation of the agents in question, but I use it in response to the existing literature on the subject by David Shoemaker and others. 
responsible for coming to the majority of their sessions as scheduled because they have psychiatric difficulties.

That said, responsibility responses to these individuals, should they fail to meet their responsibilities, typically are and should be modified in accordance with the individuals' deficits: we do not feel resentment towards a young child who blurts out the first thing on her mind, and we are often unclear how to respond when an addict struggles to maintain his sobriety, even when we would resent or blame others who behave similarly. Both the inclusion of marginal agents in some of our responsibility practices and the fact that our responses to them are modified stand in need of explanation.

Marginal agents are identified as such in virtue of the deficits they may have in the capacities typically associated with responsible agency. As such, the category is extremely broad; it includes individuals as different from each other as four-year-olds, adults with cognitive disabilities, and addicts. Nonetheless, our responsibility responses to marginal agents share some common features, as I will illustrate below. ${ }^{3}$

\section{Sunday Brunch}

You are at a restaurant on the weekend, and your five-year-old child is yelling at the top of his lungs. The restaurant is packed and your son is screaming because he is bored. At this point, many people in the restaurant probably hold you responsible for your son's screaming; his behavior

\footnotetext{
${ }^{3}$ Although these examples are hypothetical, I take them to reflect perfectly ordinary circumstances one might find oneself in during the course of one's life. I also take them to be representative of the most central aspects of our practices of holding marginal agents responsible, but this claim requires a caveat: Much of the philosophical literature about marginal agency focuses on psychopaths, and it is unclear to me that the account I give of holding marginal agents responsible would apply in any neat way to psychopaths. Those cases ought to be treated differently, however, because of the nature of psychopaths' impairments with respect to empathy and interpersonal engagement, and the limitations those specific impairments may place on psychopaths participating in the moral community, even in an attenuated sense.
} 
is obnoxious, and others would appreciate it if you could get him to calm down and be quiet. The host, for example, might wish that both of you would go outside. It also seems appropriate for you to hold your son responsible for his behavior. You might do this by telling him he needs to stop yelling and mentioning the use of "inside voices," or by telling him that if he behaves himself, you'll be leaving soon. Though these responses are different from the ways you would hold an adult responsible for similar conduct, you are certainly responding to your child's behavior by reminding him of expectations that he is not living up to, and the hope is that this reminder will motivate him to behave better. Also, though you might expect your child not to scream just because he is bored, you might not similarly expect him to abstain from screaming if he burns his tongue on hot soup, as you presumably would with most adults.

\section{Noon Somewhere \#1}

An alcoholic agrees to meet an acquaintance from work for coffee at $8 \mathrm{am}$. When they greet each other, the alcoholic seems to be acting strangely, saying odd things at full volume. The acquaintance then realizes that he smells alcohol on his colleague's breath and is unsure how to respond. On the one hand, the acquaintance may reasonably be annoyed or concerned by his colleague's behavior, but on the other, he might wonder what to say (given that being intoxicated that early in the morning makes him suspect that his colleague is an alcoholic, and he doesn't know his colleague well). It seems appropriate for him to withhold angry or judgmental responses he might have been inclined to have before realizing his colleague was drunk so early in the day.

\section{Noon Somewhere \#2}

Now imagine the same individual struggling with alcoholism who arrives similarly intoxicated to his 8am therapy appointment. It seems much more appropriate for his therapist to call him out, and insist on the importance of being sober for their appointments. In fact, a therapist who ignored this concern would strike us as negligent. 
While these cases involve many considerations having to do with responsibility, I will focus on some that are especially salient. In Sunday Brunch, there are very different expectations for how the parent and the host of the restaurant ought to conduct themselves, though both might have reason to be frustrated at the child's screaming. Similarly, both the acquaintance and the therapist of the alcoholic in Noon Somewhere may be concerned and irritated by the alcoholic's inebriated state, but there is nonetheless a contrast in how it is appropriate for them to respond.

Moreover, the reason why the restaurant host and the acquaintance might rightly bite their tongues in these circumstances is that it is arguably not their place to hold the child or the alcoholic responsible, who is more or less a stranger to them. (While the host might appropriately hold the parent responsible for how she handles her son's screaming, that is a separate matter.) The host of the restaurant would probably respond quite differently to a (presumed psychologically normal) adult who had a similar outburst in the restaurant, as would the acquaintance to a colleague who neglected social obligations with no apparent mitigating circumstances. Finally, the ways in which the parent and the therapist hold those in their care responsible is sensitive to their capacities; the parent's responses in Sunday Brunch, for example, reflect both her frustration at her son's behavior and her knowledge that it is difficult for him to control how he expresses his emotions at this age. While she may disapprove of his behavior and express this to him, the tone of her disapproval and its expression are colored by her knowledge that he is young and it would be challenging for him to behave himself in the circumstances.

In summary, these cases bring out three central features of our practices of holding responsible as they involve marginal agents:

1. The norms to which one holds marginal agents responsible may (though need not) have 
different content than those that psychologically normal adults are expected to uphold. ${ }^{4}$

2. The ways in which it is appropriate to hold marginal agents responsible may (though need not) have a different character or tone than the ways one ought to hold psychologically normal adults responsible.

3. It matters significantly what one's relationship is to a given marginal agent whether or not one should hold her responsible.

Another important thing these cases are meant to illustrate is that holding someone responsible should not be understood as synonymous with blaming her or seeing her as a fitting object of the negative reactive attitudes (e.g., resentment). As I understand it, holding someone responsible means holding her to an expectation - that is, enforcing a norm. One might do this by blaming or punishing, but also by praising, crediting, demanding an apology, or reminding someone what we expect of them going forward.

\section{Possible Explanations}

Below, I will consider some accounts of why we hold marginal agents responsible in the particular ways that we do (that is, why 1,2, and 3 above are true). To state the explananda explicitly, we need to account for the fact that we include marginal agents in some of our responsibility practices at all, despite judging that they are deficient in the capacities typically associated with responsible agency, and we must also account for the three features above that describe the

\footnotetext{
${ }^{4}$ Though I will go on to argue that all four of the candidate explanations I consider for how we hold marginal agents responsible can explain this feature, it is not entirely uncontroversial. Scanlon, for instance, writes, "We do not blame young children for things such as rudeness or self-centeredness in the same way that we would blame an adult. This is not because the relevant standards of conduct are different for children. We would not say to a child, 'It is all right to hit people now, since you are a child, but don't do it later when you are grown up"' (Scanlon 2008: 156). But in Sunday Brunch, it seems plausible that the child might be responsible for not screaming because he's bored, though not responsible for not screaming after burning his tongue, though ordinarily we would regard adults as responsible for not screaming in either case. Arguably, then, some of the relevant standards of conduct are different for children, which is all I am claiming.
} 
character of that holding responsible. Before arguing for my own view, which is that we hold marginal agents responsible largely in virtue of norms that arise in the context of certain kinds of relationships, I will consider three alternatives: the pretense view, the degrees of responsibility view, and Shoemaker's tripartite view of responsibility. Ultimately, I will argue that these other explanations are inadequate, primarily because they do not explain the third feature — that is, they fail to account for the vital role that our relationships to marginal agents play in our practices of holding them responsible.

\section{3a. The pretense view}

According to the pretense view, we include marginal agents in our responsibility practices only in a derivative sense. The account is roughly the following: some individuals who are in close relationships with marginal agents (especially their caregivers) have to teach them how to behave and how to take responsibility for their behavior, and the most effective way to do this is by holding them responsible. That said, parents of young children, for example, are well aware that their children are not really responsible, and this knowledge undermines the possibility that holding them responsible could be entirely genuine. When we hold psychologically normal adults responsible, we do so in virtue of believing that they display a level of normative and agential competence that marginal agents don't have, but we can pretend marginal agents have this competence for the sake of helping them to develop the relevant capacities and learn moral norms. Any justification for our practices of holding marginal agents responsible on the pretense view comes from the instrumental 
role those practices play in helping to integrate marginal agents into the moral community, and teaching them how to behave properly., 5

There is a kernel of truth in the pretense view, namely that holding marginal agents responsible is often an important part of moral education, and as such is frequently predicated on the aspirations those in close relationships with marginal agents have for their growth and development. But the motivation for endorsing the pretense view comes from a theoretical commitment I am questioning, namely that genuinely holding someone responsible is only justifiable if one believes that they possess a relatively high degree of normative and agential competence. Although this commitment is a part of much of the philosophical literature on responsibility, it has substantial costs.

\footnotetext{
${ }^{5}$ For one statement of this view, see Vargas' Building Better Beings. Vargas claims that though “...young children might well be responsible agents in very specific or local circumstances... it seems fair to characterize a good deal of parenting and acculturation as bent to the task of expanding the range of circumstances in which the targets have the capacities required for moral responsibility. Initially, much of this happens via feigned attributions of responsibility. In contrast to genuinely holding someone responsible, moral education is typically undertaken in the way characterized by traditional moral influence theorists, that is, with the aspiration of influencing. There is no assumption that the target is a responsible agent. Indeed, the point of feigning praise and blame just is to get children to such a point where they have the capacities that are required for genuine praise and blame. In contrast, holding someone morally responsible assumes the relevant capacities are present and that the agent has failed to demonstrate the appropriate form of moral concern." (Vargas 2013: 229).

${ }^{6}$ See also Wallace's (1994) discussion of children's responsibility in Responsibility and the Moral Sentiments. He writes, "Because children lack... [the powers of reflective self-control]...or are still in the process of acquiring them, it would be unreasonable to hold them fully accountable with respect to the moral obligations we accept. But of course we often treat them as if they were accountable agents when they violate those obligations... [P]artly it is because treating children as if they were responsible is believed to be the most effective way to stimulate the development of their powers of reflective self-control" (Wallace 1994: 167, emphasis in original). Wallace's complete view on holding children responsible, however, is actually a hybrid of the pretense view and the degrees of responsibility view below. Darwall also offers a similar account of holding children responsible in his discussion of 'non-central cases' in The Second Person Standpoint (Darwall 2006: 86-8).
} 
Holding marginal agents responsible is an essential part of many relationships those agents have, and in those contexts, it doesn't seem like just a noble lie. In other words, when parents hold their children responsible, most conceive of themselves as doing so genuinely and not merely with an eye toward behavior modification. An analogous point seems to hold in therapeutic relationships, where therapists hold their patients responsible in a way that ideally reflects their respect for their patients' agency as well as the desire for them to avoid self-destructive behavior. It is important to respect the phenomenology of those relationships, where recognition of a marginal agent's limitations doesn't preclude authentically holding her responsible, though it may require modifying some of our ordinary responsibility responses. If we are not forced to describe those practices as a kind of pretense whose justification is merely instrumental, we should avoid doing so.

\section{3b. The degrees of responsibility view}

The pretense view also offers no substantive explanation for the three aforementioned features of our practices of holding marginal agents responsible, though it is compatible with them. There are alternative views, however, that do have more to say by way of explanation of those features. One straightforward way to understand how we might hold marginal agents responsible despite their being deficient in the capacities typically associated with responsible agency is to say that there are degrees of responsibility. We hold marginal agents responsible because they are responsible, but to a lesser degree than psychologically normal adults. ${ }^{7}$ At first glance, this view seems quite plausible: many of the conditions that make someone count as a marginal agent, including childhood and many psychiatric difficulties, are experienced temporarily. Outgrowing or

\footnotetext{
${ }^{7}$ Coates and Swenson (2013), who are proponents of one version of this view, explain degrees of responsibility in terms of degrees of reasons-responsiveness. Tiboris (2014) develops a similar view about children in particular according to which they are less responsible because they have diminished normative competence. There could well be other views in the same family that focus on other capacities that are regarded as both necessary for responsible agency and that admit of degrees.
} 
overcoming such conditions plausibly includes growth in the capacities associated with responsible agency.

Moreover, facilitating such growth may require holding those agents responsible while acknowledging that their capacities for self-control or rational deliberation may be limited. As Strawson writes,

"Parents and others concerned with the care and upbringing of young children...are dealing with creatures who are potentially and increasingly capable both of holding, and being objects of, the full range of human and moral attitudes, but are not yet truly capable of either. The treatment of such creatures must therefore represent a kind of compromise, constantly shifting in one direction, between objectivity of attitude and developed human attitudes. Rehearsals insensibly modulate toward true performances" (Strawson 2008: 20).

This point of Strawson's is related to the first two features I described as central to our practices of holding marginal agents responsible: the restricted scope of the normative demands we can appropriately place on these agents (in this case, children), and the ways in which enforcing those demands is colored by knowledge of the agent's present limitations and her potential to overcome them. The compromise Strawson mentions is reflected in the fact that marginal agents participate in some of our responsibility practices, but our responses to them are modified in light of their deficits.

The degrees of responsibility view, if true, would explain why the normative expectations that are properly placed on marginal agents may be less demanding, and may be enforced in different ways, namely because this reflects an understanding of marginal agents' limitations. A therapist might believe that her patient ought to quit drinking entirely, for example, but knows this is a tall order. In light of that, she might set smaller, more manageable goals for his alcohol use (e.g., that he cut back to a certain amount and disclose how much he is drinking to her), and enforce these goals without the use of anger and resentment that are common parts of interpersonal blame with psychologically normal adults. What the cases I've described invite us to see, however, is that introducing the notion of degrees of responsibility is not sufficient to understand our responsibility responses to marginal agents. In particular, it does not capture the differences between the ways 
those in close relationships with marginal agents are entitled to hold them responsible in comparison with mere strangers or acquaintances.

If all that was going on in Sunday Brunch, for example, was that a young child is less responsible and should therefore be held less responsible for his screaming than a psychologically normal adult, then it would be just as appropriate for the host of the restaurant to hold the child responsible as for the parent to do so. But this is false; I take it that most parents would respond to the host holding the child responsible by saying that the host is out of line, and many parents would accept responsibility for the child's screaming even if they did nothing to cause it. The parent-child relationship seems to play an essential role in understanding this case, and the degrees of responsibility view cannot account for this on its own. A similar, though less striking, contrast holds between the acquaintance and the therapist in Noon Somewhere \#1 and \#2.

\section{3c. Shoemaker's tripartite view of responsibility}

In his recent book, Responsibility from the Margins, David Shoemaker develops a view of responsibility that tries to account for much of the complexity involved in holding a wide range of marginal agents responsible. Unlike the degrees of responsibility view, Shoemaker doesn't characterize the deficits of marginal agents in terms of their being at a different point on a unified responsibility scale from psychologically normal adults. Instead, he characterizes our primary attitude about holding marginal agents responsible as ambivalence - not because we're uncertain about whether or not they are responsible, or just how responsible they are, but rather because, "[t] hese are agents who often strike us as ineligible only for some subset of responsibility responses while nevertheless being fully eligible for others" (Shoemaker 2015: viii).

Following Strawson, Shoemaker views responsibility as being essentially connected to the reactive attitudes (e.g., gratitude, resentment, and indignation) and thereby to the quality of an agent's will. As Strawson writes, “The reactive attitudes... are essentially reactions to the quality of 
others' wills towards us, as manifested in their behavior: to their good or ill will or indifference or lack of concern" (Strawson 2008: 15). For example, I might feel resentment towards someone who intentionally pushes past me in line because he is displaying disregard towards me (as well as others in the line), and expressing this resentment would be one way of holding him responsible.

Shoemaker locates the source of our ambivalence about holding marginal agents responsible in the claim that 'quality of will' is ambiguous between three senses that can come apart. ${ }^{8}$ As such, he claims that we need to understand responsibility as admitting of three corresponding senses: attributability, accountability, and answerability. We are ambivalent in the sense Shoemaker describes because marginal agents are responsible in some of these senses but not all (Shoemaker 2015: viii).

To his credit, Shoemaker spends considerable effort attending to the empirical details of different conditions that afflict marginal agents and the consequences of those details for his account of responsibility. His account is thus capable of providing a fine-grained analysis of why the norms to which we hold specific marginal agents responsible might have different content and conditions of enforcement (i.e., the first two features I referred to above). But Shoemaker offers no real explanation for the third feature, namely why one's relationship to a given marginal agent should matter so profoundly in determining whether or not one is entitled to hold her responsible. ${ }^{9}$ In fact,

\footnotetext{
${ }^{8}$ Shoemaker calls these three senses "quality of character, quality of judgment, and quality of regard" (Shoemaker 2015: viii). They define quality of will in terms of one's character traits, one's capacity for judgment and rational self-governance, and the regard or concern one has for others, respectively (Shoemaker 2015: 10-13). Though these details are important for having a full understanding of Shoemaker's view, they are not relevant for my purposes.

${ }^{9}$ More recently, Shoemaker (2017) has defended a response-dependent view of responsibility. His discussion of this view focuses on blameworthiness and its connections to anger. He characterizes this view as follows: "The blameworthy (in the realm of accountability) just is whatever merits anger (the anger-worthy); that is, someone is blameworthy (and so accountable) for $\mathrm{X}$ if and only if, and in virtue of the fact that, she merits anger for X" (Shoemaker 2017: 508). The sense of meriting in question for Shoemaker is to be understood in terms of D'Arms and Jacobson's (2000) "fittingness" framework. Though this is a view on which holding responsible is metaphysically prior to being responsible, Shoemaker nonetheless seems to think that the targets of our responsibility responses
} 
he seems committed to locating the differences between how we hold marginal agents responsible and how we hold psychologically normal adults responsible in capacities internal to these agents rather than in their interpersonal relationships. ${ }^{10}$

Interestingly, Shoemaker notes that with at least some kinds of marginal agents, those in close relationships to those agents have fairly robust responsibility responses while others do not. As he writes, “...with their caregivers, friends, and family, adults with mild intellectual disabilities (MID) are quite often treated as full-fledged moral agents (at least with respect to a subset of moral demands), susceptible to full-throated reactive emotions and other responsibility responses" (Shoemaker 2015: 31). Moreover, these responsibility responses on the part of caregivers and loved ones seem to achieve uptake. As Shoemaker writes, “Adults with MID seem generally able to understand the emotional communications of agential anger and gratitude as such, see and appreciate the distress associated with injuries and harms to others as reasons of the right sort, and feel what the injured or harmed party feels in being so affected”' (Shoemaker 2015: 185).

“...[S]trangers (who are aware of...[their conditions]...) but who are not in...[close] relationships... with those with MID," however, "may think that [individuals with such disabilities]

are agential capacities of individual agents. As he writes, “...[D]ifferent responsibility emotions could target very different agential capacities, which could well mean that they implicate different types of responsibility" (Shoemaker 2017: 521). If he is committed to his response-dependent methodology in a thoroughgoing way and grew to be sympathetic to the thought that our relationships play an irreducible role in making certain types of responsibility responses fitting or unfitting, then his view would be compatible with mine. But this would be quite a substantial departure from his extended (2015) treatment of responsibility and marginal agency, and does not seem to be something he has in mind even in the (2017) paper.

${ }^{10} \mathrm{He}$ also gives the following schematic way of characterizing how responsibility attributions are to be understood: "To be a responsible agent is to be worthy of $\mathrm{X}$ for $\mathrm{Y}$ in virtue of $\mathrm{Z}$, where $\mathrm{X}$ refers to some kind of "praising" and "blaming" responsibility responses, Y refers to something like actions or attitudes, and Z refers to the responsibility-maker, be it, for example, one's capacity for reasons-responsiveness, one's capacity for having and expressing one's deep self, or, as Strawson would have it, one's capacity for having a quality of will" (Shoemaker 2015: 17). Notice that all of the candidate responsibility-making capacities Shoemaker proposes are internal in the way I've described. 
may not be able to recognize them as a fellow member of the accountability community..." and are therefore reluctant to hold them accountable (Shoemaker 2015: 187). Shoemaker writes that, “...such reluctance may be appropriate. Because of their developmental impairments, adults with MID may indeed have difficulty...accessing or appreciating abstract principles about mutual recognition and accountability amongst all members of the accountability community" (Shoemaker 2015: 187). In other words, while people with MID experience empathy and other moral emotions when observing someone in distress, for example, they may have difficulty understanding practical demands, expectations, or criticism placed on them by strangers. In contrast, they may well understand robust responsibility responses on the part of caregivers and others with whom they are in close relationships, and presumably those relationships themselves play an important role in securing that understanding.

Shoemaker accounts for how a caregiver's, friend's, or relative's relationship to an individual with MID can inform her appropriately holding that individual responsible by focusing on how that relationship facilitates the person with MID's understanding of the relevant practical demands. It may be true that people with MID better understand practical demands given by their caregivers and loved ones, and this may partially explain why these relationships are typically the only ones that involve "full-throated" responsibility responses. But Shoemaker still holds that the sense in which individuals with MID are responsible is solely a function of capacities internal to them, and therefore makes their relationships incidental to their responsibility. Moreover, this kind of account about the role of relationships in our responsibility practices doesn't generalize to the full range of marginal agents. ${ }^{11}$ For example, it doesn't seem to be a lack of understanding of social norms that keeps the

${ }^{11}$ There are important differences among the conditions that make individuals count as marginal agents, so being unable to provide a general account of how relationships affect responsibility responses to these agents is not a decisive objection to Shoemaker's view. I mean only to put pressure on the idea that the best way to understand why those close to individuals with MID have 
alcoholic from arriving at his appointments sober, and he would understand his acquaintance and his therapist holding him responsible equally well. What seems to be at issue here is not only the relevant responsibility responses being intelligible because of the relationship between the agents in question, but those responses being appropriate given the nature of that relationship.

\section{3d. The relationship-based norms view}

While there are important differences between the three views I've considered above, they all locate the differences between how we hold marginal agents responsible and how we hold psychologically normal adults responsible solely in capacities internal to those agents. But this distorts the phenomena of interest. We cannot understand our practices of holding marginal agents responsible without recognizing that our relationships to these agents have a fundamental role to play in those practices.

\section{i. The limits of standing}

There have been some attempts in the philosophical literature to capture how our relationships to a person or their actions impact how we especially should respond to them in light of what they have done. One central notion in this literature is 'standing to blame.' The thought behind this notion is that whether a blameworthy individual should in fact be blamed depends not only on whether or not they are responsible for doing something bad but also on whether anyone bears the appropriate kind of relationship to the person's actions such that they can rightly issue blame (i.e., has standing to blame). ${ }^{12}$ On a standard view of this notion, agents must meet the

\footnotetext{
"full-throated" responsibility responses to them while others refrain from doing so is solely in terms of those individuals' capacity to understand their respective practical demands.

12 There are many conceptions of blame and what it requires. The differences among these views are substantial, but they are not the central focus of this paper, and what I say about the notion of standing is neutral between them. In particular, my claim that the host of the restaurant has standing to blame the child, though it is nonetheless inappropriate for her to do so, does not depend on thinking that blame must be expressed publicly.
} 
following conditions in order to have standing to blame:

1. They must have an identifiable stake in the wrongdoing in question (i.e., it must be their business).

2. They must be contemporaries (i.e., part of the same moral community) as the potential target of blame.

3. They must not have engaged in similar wrongdoing in the past such that their blame would be hypocritical.

4. They must not be responsible for or complicit in the wrongdoing.

If all of the potential blamers for a wrongful action fail to meet these conditions, then those who endorse the notion of standing would claim that blame is inappropriate even though the individual who performed the action is blameworthy (Bell 2013: 264).

The notion of standing is not particularly illuminating for understanding how our relationships matter to our responsibility responses to marginal agents. Invoking standing does introduce some relational considerations with respect to the appropriateness of blame - specifically, that the blamer and target of blame must be contemporaries, and the blamer must avoid hypocrisy, complicity, and nosiness in relation to that particular action. But these conditions entail little if anything about the nature of the relationship between the blamer and target of blame, which seems to be a vital part of an adequate description of the cases at hand. ${ }^{13}$ For example, on the standard conception of standing, it looks as though the host at the restaurant would have standing to blame

\footnotetext{
${ }^{13}$ One might think that whether a particular wrongful action is one's business is a reflection of the relationship between the potential blamer and target of blame, but this need not be so. For example, the child's screaming is the business of the restaurant staff because it is their job to accommodate other customers, not because of any relationship between the staff and the child. Nonetheless, we would typically regard it as inappropriate for the restaurant staff to hold the child responsible.
} 
the five-year-old screaming in her restaurant, though it nonetheless seems inappropriate for her to do so.

\section{ii. Relationships as sources of norms}

The key to understanding how relationships inform our responsibility responses to marginal agents is to view close relationships as sources of some of the norms we expect these agents to uphold. The reason why the parent but not the host in Sunday Brunch is entitled to hold her child responsible is that she has established expectations with her son for his behavior, where there are consequences for violating those expectations. While there might be general expectations that people behave respectfully and considerately in public spaces, the child in this example would not generally be viewed as responsible for upholding them yet, which explains the apparent inappropriateness of his being held responsible by the restaurant staff or other strangers. Until he is able to appreciate and uphold those general expectations, he is only responsible for upholding relationship-based norms in this domain. ${ }^{14}$ This is not to say that children, or marginal agents more generally, are only subject to relationship-based norms. Rather, in domains where they are impaired or immature, some general norms may be offline, though they may be subject to relationship-based norms with overlapping (though perhaps less demanding) content.

When parents hold their children responsible, this often serves an educative function. ${ }^{15}$ More

\footnotetext{
${ }^{14}$ The term 'relationship-based norms' is derived from 'relationship-dependent norms,' which was introduced by Macalester Bell in "The Standing to Blame: A Critique" in order to explain how "blame's moral propriety sometimes depends on the relationship between the blamer and the target [of blame]" without invoking the notion of standing, which she finds problematic (Bell 2013: 265). In the development of this notion, I am strongly indebted to her.

${ }^{15}$ Saying that our responsibility responses to children serve an educative function does not preclude them from being genuine instances of holding responsible. Though moral education is an important part of childrearing, it is not as though our moral education stops once we become adults. Holding anyone responsible, regardless of their maturity, can be a way of drawing their attention to important considerations they may be unaware of or have otherwise overlooked. This point is of a piece with
} 
specifically, it is a way of modeling important aspects of the norms of the wider moral community, both in terms of their content and what happens when they are violated. This allows children to learn what constitutes making a moral mistake, and the consequences that particular mistake would have for their interpersonal relationships. But it also insulates children from overly harsh treatment while they are learning how they are supposed to behave, how to control themselves, and how their behavior affects others.

An analogous point can be made about Noon Somewhere. The reason why the therapist should hold the alcoholic responsible for showing up intoxicated is that their relationship is partially constituted by certain expectations about how both parties ought to behave. Some of those expectations would be a part of all relationships that are genuinely therapeutic. For example, a therapist must have some hope that her patient can recover, and the patient must make a good faith effort to attain recovery (which would presumably include showing up to appointments sober). Other expectations that are part of therapeutic relationships will be more specific, and ideally, they will be established as a result of the patient's desired aims for treatment and the therapist's judgment about what is necessary and realistic in order for her to achieve those aims. In contrast, the relationship between the acquaintance and the alcoholic is currently fairly distant and unstructured, and consequently it is not a source of relationship-based norms in the same way. ${ }^{16}$ An attentive acquaintance might be bothered by his alcoholic colleague's behavior at their meeting, but would also recognize that this same behavior indicates that something is seriously wrong with his colleague.

the view that blame paradigmatically serves a communicative function. For one statement of this view, see Fricker (2016).

${ }^{16}$ The point here is not that only a therapist could hold the alcoholic responsible for being sober at social engagements, but that relationship-based norms give relationships a certain structure, and therefore they tend to require a level of intimacy that is not had between strangers or acquaintances. 
He should therefore, at the very least, hesitate about whether to hold his alcoholic colleague

responsible, given this evidence of his impairment, and given that they are only acquaintances. By

entering into therapy, however, the alcoholic has thereby created a relationship that is intended to be

a source of norms about his drinking, and therefore his therapist can (and ordinarily should) hold

him responsible for attending their appointments sober. ${ }^{17}$

When therapists hold their patients responsible, this serves a number of important

functions. ${ }^{18}$ For example, most patients know about the norms they are expected to uphold as a

member of the moral community, but may be unsure whether or not they're capable of living up to

them; the role of the therapist is to facilitate growth in this latter arena, and thereby help those

patients reintegrate into the community. Depending on the duration and severity of their illness,

psychiatric patients may have strong inductive evidence that they can't do what they must to avoid

${ }^{17}$ A proponent of the notion of standing to blame might insist that a more proximate explanation here is that the alcoholic's drinking is his therapist's business, and not the acquaintance's. But even if the alcoholic's drinking is generally not the acquaintance's business, his drunkenness at their meeting surely is, so this cannot explain the difference between the two cases.

${ }^{18}$ My views about the importance of holding responsible in therapeutic relationships share some commonalities with Pickard's (2013) "responsibility without blame" framework. Pickard, however, claims that the sense in which people with mental disorders are responsible is non-moral because "behaviors like self-harm, substance abuse, and obsessive rituals, can be damaging to the person without necessarily damaging others" (Pickard 2013: 1150). Moreover, she claims that if therapists regarded their patients as morally at fault for their behavior, they would regard themselves as entitled to subject those patients to the negative reactive attitudes, which would undermine the effectiveness of their treatment. I am broadly sympathetic to Pickard's view about how it is appropriate to hold patients responsible without subjecting them to negative reactive attitudes in the context of therapeutic relationships. I believe, however, that we can (and should) understand the significance of this without invoking a different, non-moral sense of responsibility. In some cases, it seems fitting to recognize that psychiatric patients are responsible for wrongful actions they perform but excuse them from the negative reactive attitudes because they do not deserve them given the nature of the difficulties that they face. And one might think that therapists are obliged to exhibit a degree of emotional detachment towards their patients that is incompatible with the negative reactive attitudes. Thus, holding responsible may entirely avoid these attitudes, even if one is still considering moral responsibility. 
running afoul of what is expected of them. At least for many, those expectations seem so demanding that they lack the consistent motivation or self-control to do what they might acknowledge they should. As Flanagan writes in a discussion of identity and addiction,

"Alcoholics and drug addicts often speak about no longer being themselves, of having lost their way, and loved ones, friends, the law, and the mental health community typically agree. The adult addict is physically continuous with some particular baby born years before, and they have an autobiographical memory of that particular individual life. Metaphysically speaking, the addict is the same person they always were. But they are no longer the person they planned, hoped, or expected to be, or who others expected them to be. The kind of identity they have lost or are in danger of losing is the kind of identity that comes from executing authorial power to align, keep aligned, and then continually recalibrate one's actual life in terms of one's vision of the good" (Flanagan 2018: 77).

One of the aims of holding addicts responsible in the context of psychotherapy, then, is to restore that authorial power and its connection to the addict's identity.

But what is it about therapeutic relationships that makes it possible for therapists to facilitate that restoration? More generally, what do the kind of relationships in which it makes sense to hold marginal agents responsible have in common? So far, I have primarily talked about parents holding their children responsible and therapists holding their patients responsible, but I do not mean to suggest that caregiving relationships are the only ones in which one could appropriately hold marginal agents responsible, or the only kinds of relationships that could be sources of norms.

They are, however, paradigm instances of a broader range of close relationships. Close relationships are ones where the members tend to care especially about each other's approval, and where the parties in question have the authority to expect each other to act in accordance with their values, as individuals or as members of the relationship. The importance of relationships to responsibility may be especially obvious when responsible agents are also impaired or immature. For better or for worse, children can't raise themselves, and people with psychiatric issues who enter into therapy thereby acknowledge that they'd be better off not going it alone. But all of us participate in close relationships that are partially constituted by relationship-based norms. Consider, for example, 
the norms that people stipulate in the context of their romantic relationships about how frequently they communicate, or who will perform various domestic tasks, or how they will raise their children. That said, relationship-based norms play a more obvious role in marginal agents' lives because some of the expectations that we usually hold of people may need to be adjusted in light of their deficits, and it is especially important for there to be a good fit between one's responsibility responses to them and their capacities. ${ }^{19}$

\section{iii. Explaining the cases at hand}

Now, let us consider how the relationship-based norms view accounts for the three features of our practices of holding marginal agents responsible that I've discussed so far. The first such feature is that the content of the norms to which marginal agents are subject sometimes differs from the norms we generally expect psychologically normal adults to uphold. To revisit Sunday Brunch, though a parent might have a normative expectation that her five-year-old child not scream in a restaurant solely because he's bored, she might not have a similar expectation that he shouldn't scream if he burns his tongue on hot soup, whereas this is presumably something we expect of most adults. My explanation for this feature is as follows: Relationship-based norms aim to be sensitive to the capacities of the agents in those relationships, and to reflect the understanding both parties in the relationship have of each other. The conditions that make specific persons count as marginal

\footnotetext{
${ }^{19}$ This point is nicely made with respect to children by Tamar Schapiro in her paper, "What Is a Child?" She argues that childhood is a normative predicament that children have to be guided out of in order to become autonomous, where this guidance involves sensitivity to their present capacities as well as acknowledgement that they will develop over time. As she writes, "Some readers have worried that the view I am putting forth implies that we ought to force children to take on adult responsibilities as early as possible, to 'throw them in the deep end,' as it were. But when a child (or any person, for that matter) is forced to perform tasks which are overly demanding given her abilities, this tends merely to reinforce her sense of her own dependence and powerlessness. Children should be given tasks which are challenging yet tractable, tasks which allow them to feel pleasure in their own achievement of mastery" (Schapiro 1999: 737).
} 
agents present obstacles to their meeting the demands of the moral community in those domains where they are impaired. Most five-year-olds, for example, find it quite difficult to control themselves, and the fact that they are in a public space won't prevent them from yelping if they are in pain.

That said, the content of relationship-based norms doesn't always differ in this way. In the example we've just considered, the parent has established a norm that her five-year-old shouldn't scream in the restaurant when he is bored. This may well be more difficult for a typical five-year-old than it would be for most adults, but it is presumably a reasonable expectation for both. Moreover, given the role that holding marginal agents responsible plays in their growth and development, it makes perfect sense that the norms they are responsible for upholding share some of their content with those to which psychologically normal adults are subject.

The relationship-based norms view accounts for the second feature of our practices, namely that the character of our responsibility responses towards marginal agents may differ from how we would hold psychologically normal adults responsible, along similar lines. With both children and addicts, there is a recognition that the condition that makes them count as marginal agents also makes living up to certain expectations of the wider community especially difficult, whether due to emotional distress or a developing understanding of those expectations. Appropriate responsibility responses to these individuals take those considerations into account, and may therefore take on a different (e.g., less angry) tone.

Finally, the relationship-based norms view's explanation for the third feature of our practices, namely that one's relationship to a given marginal agent matters with respect to whether or not it is appropriate for one to hold her responsible is, at a very general level, trivial. After all, what distinguishes this view from alternatives is primarily that it explains some of our responsibility responses in terms of norms established in the context of particular relationships. Nonetheless, it is 
less trivial to determine which relationships are sources of norms of this kind, and when agents are subject to them. ${ }^{20} \mathrm{I}$ have suggested that a special concern for the good opinion of the other party and a shared evaluative perspective characterize relationships that are sources of norms.

The other views I have considered all take it for granted that there is such a thing as being a responsible agent, and that agents attain this status solely in light of capacities internal to them. The examples we have considered cast doubt on this assumption. On the pretense view, marginal agents lack the capacities required to be responsible, and therefore holding them responsible must be a matter of pretense. On the degrees of responsibility view, the fact that marginal agents have deficits in the capacities required for responsible agency (e.g., normative competence on Tiboris' view) is what explains their diminished responsibility. On Shoemaker's tripartite view of responsibility, marginal agents are likewise responsible in some senses but not others in virtue of the state of their internal capacities (specifically, their capacities for having and expressing a deep self, their ability to answer for their actions, and their regard for others). On all these views, moreover, the justification for holding someone responsible is tied to these capacities.

The relationship-based norms view offers an alternative conception of responsibility. On this view, whether one counts as responsible, and whether someone is entitled to hold one responsible, is a relational matter all the way down. In order to act according to norms, agents must have certain capacities, but which capacities these are will depend on the norms in question. The norms themselves, however, are what is most fundamental to responsibility. The capacities of individual agents are relevant to responsibility to some extent, but their relevance is always mediated by social considerations. For example, the child is responsible to his parent for not screaming in the

${ }^{20}$ This uncertainty about whether or not a relationship-based norm holds between particular parties could serve as an alternative explanation for what Shoemaker calls our ambivalence with respect to the responsibility of marginal agents that does not require his three senses of responsibility. 
restaurant, and the parent is entitled to hold her child responsible for this, because of a norm that holds between them, and not simply because of the child's ability to do what that norm requires. In this example, the child is responsible full stop - not pretend-responsible, or responsible to a degree. Similarly, I may be responsible to my partner, and he may be entitled to hold me responsible, for communicating every day when one of us is traveling, if there is a norm like this between us. Our relationships are foundational to responsibility, not only in bringing us up in the moral community, but in continuing to be sources of norms throughout our lives; we cannot be responsible by ourselves.

\section{Conclusion}

Friendships (as well as parent-child relationships, romantic relationships, and so on) vary quite a bit from each other, and therefore relationship-based norms take on a variety of different forms. At the most general level, these norms seem to fulfill two roles: First, relationship-based norms allow the parties in a particular relationship to establish how they want to be with each other. In this role, relationship-based norms concern matters that are strictly internal to a particular relationship (e.g., who takes out the trash). Many of these matters are quite mundane, although they can also be weightier (e.g., establishing what fidelity requires for you and your romantic partner). Regardless, establishing norms that are appropriate for a particular relationship partially constitutes the relationship itself.

Second, relationship-based norms sometimes concern matters in the wider community, where the relationship is such that the parties can motivate each other to act and feel in certain ways in response to each other's expectations. Relationship-based norms that play this second role also apply to marginal and non-marginal agents alike. Sometimes these norms arise because agents are impaired or immature, and sometimes they simply reflect the authority that our kith and kin have to hold us accountable for acting in accordance with our values. For example, if I tell a friend that I 
intend to be an ethical vegetarian from now on, she has grounds to hold me responsible if she finds me eating meat that strangers or acquaintances would presumably lack. ${ }^{21}$

The claim that marginal agents, including children, are subject to relationship-based norms in domains where they are impaired or still developing suggests a way of understanding the apparent plausibility of the degrees of responsibility view. On my view, our responsibility responses to marginal agents are modified in ways that reflect the difficulties they face in living up to some of the demands of the moral community. Rather than concluding on this basis that marginal agents are responsible, but to a lesser degree, I've invited us to notice that there are particular relationships in which marginal agents rely on others to help them navigate and resolve these difficulties. In the context of these relationships, I have argued, marginal agents are appropriately held responsible.

Still, one might wonder where this leaves us with respect to the question of whether and to what extent marginal agents genuinely are responsible. After all, I haven't denied that marginal agents have genuine deficits that, at least for the time being, affect what they are capable of and the expectations to which they are reasonably subject. Why should we think of my view, that stresses the importance of relationships, as a competitor to the degrees of responsibility view rather than a variation of it? I am not fundamentally objecting to the claim that there are degrees of responsibility (or indeed, that there can be pretense in our responsibility practices). I am objecting to these views as explanations for how we hold marginal agents responsible in ordinary life. I have tried to show that these practices put pressure on any view of responsibility that characterizes it as a property of individual agents, possessed in virtue of capacities such as rationality and self-control.

\footnotetext{
${ }^{21}$ It might be the case that strangers or acquaintances would have some grounds to hold me responsible for eating meat if it is morally obligatory for me to abstain from doing so. However, these are not the same grounds that my friend has on the basis of my telling her about my ethical commitment.
} 
For marginal and paradigm responsible agents alike, on my view, responsibility is always responsibility to someone. As such, the deficits that marginal agents have do not thereby mean they are responsible to a lesser degree, or only pretend-responsible. Another way to put what I am saying here, then, is that if we make being responsible a function of the psychological capacities of individual agents, we are forced to consider impaired and immature agents marginal. But we do not (or at least should not) treat them as marginal in our responsibility practices. For this reason, we ought to understand responsibility in relational terms.

I have suggested that to be responsible in some domain is to be subject to norms in that domain, and marginal agents are clearly subject to norms. The child in Sunday Brunch is responsible for not yelling in the restaurant when he's bored, and that is because he is subject to a relationshipbased norm with his parent that establishes that expectation for him. Similarly, the alcoholic in Noon Somewhere is responsible for showing up to therapy sober because of a relationship-based norm with his therapist. Paradigm responsible agents are likewise subject to relationship-based norms in some of their relationships.

Admittedly, there remain questions about what precisely is involved in being subject to a relationship-based norm, and to what extent those norms are continuous with other kinds of norms and obligations. ${ }^{22}$ But we can see how responsibility theorists must address these sorts of questions about the relational features of responsibility in order to fully understand our social practices of holding people responsible. Careful attention to these practices brings the notion of having responsibilities to other people closer to the notion of being responsible than existing accounts of responsibility typically have. We can be responsible in virtue of expectations that are established in

\footnotetext{
${ }^{22}$ By saying that responsibility is always responsibility to someone, I am not committing myself to the view that all norms to which agents are subject are relationship-based norms. I agree with Wallace (2011), for example, that "[m]oral requirements may be understood as relationshipconstituting, but they are not relationship-based" (Wallace 2011: 363, emphasis in original).
} 
the context of specific relationships or communities, as is evidenced by the cases involving marginal agents I've discussed.

I began by noting that much of the philosophical literature about responsibility addresses the question of what it takes for an agent to be responsible. I have argued that we should instead be asking what it takes for an agent to be responsible to someone for something. If we address questions about relational phenomena solely by considering individuals, we will arrive at answers that are incomplete at best. Attempting to understand being responsible as something we are by ourselves limits and thereby distorts our understanding of who is capable of responsible agency. 


\section{References:}

1. Bell, Macalester (2013) “The Standing to Blame: A Critique”. In J. Coates \& N. Tognazzini (eds.), Blame: Its Nature and Its Norms (Oxford: Oxford University Press), 263-281.

2. Brink, David O. \& Nelkin, Dana K. (2013) "Fairness and the Architecture of Responsibility". Oxford Studies in Agency and Responsibility, 1, 284-313.

3. Coates, D. Justin \& Swenson, Philip (2013) "Reasons-responsiveness and Degrees of Responsibility". Philosophical Studies, 165(2), 629-645.

4. D'Arms, Justin, and Daniel Jacobson (2000) “The Moralistic Fallacy: On the 'Appropriateness' of the Emotions". Philosophy and Phenomenological Research, 61, 65-90.

5. Darwall, Stephen L. (2006) The Second-Person Standpoint: Morality, Respect, and Accountability. Cambridge: Harvard University Press.

6. Flanagan, Owen (2018) "Identity and Addiction". In H. Pickard \& S. Ahmed (eds.) The Routledge Handbook of Philosopby and Science of Addiction (New York: Routledge), 77-89.

7. Fricker, Miranda (2016) "What's the Point of Blame? A Paradigm Based Explanation". Noûs, 50(1), 165-183.

8. McKenna, Michael (2012) Conversation \& Responsibility. Oxford: Oxford University Press.

9. Pickard, Hanna, with commentary by Ward, Lisa (2013) "Responsibility without Blame: Philosophical Reflections on Clinical Practice”. In K.W.M. Fulford, M. Davis, R.G.T. Gipps, G. Graham, J.Z. Sadler, G. Stanghellini, T. Thorton (eds.), The Oxford Handbook of Philosophy and Psychiatry (Oxford: Oxford University Press), 1134-1154.

10. Scanlon, Thomas (2008) Moral Dimensions: Permissibility, Meaning, Blame. Cambridge: Harvard University Press.

11. Schapiro, Tamar (1999) "What is a Child?". Ethics, 109(4), 715-738.

12. Shoemaker, David (2017) "Response-Dependent Responsibility; or, A Funny Thing Happened on the Way to Blame”. Philosophical Review, 126(4), 481-527.

13. Shoemaker, David (2015) Responsibility from the Margins. Oxford: Oxford University Press

14. Smith, Angela M. (2007) “On Being Responsible and Holding Responsible”. Journal of Ethics, 11(4), 465-484.

15. Strawson, P. F. (2008) "Freedom and Resentment". In Freedom and Resentment and Other Essays. New York: Routledge.

16. Tiboris, Michael (2014) "Blaming the Kids: Children's Agency and Diminished Responsibility". Journal of Applied Philosophy, 31(1), 77-90. 
17. Vargas, Manuel (2013) Building Better Beings: A Theory of Moral Responsibility. Oxford: Oxford University Press.

18. Watson, Gary (2004) "Responsibility and the Limits of Evil: Variations on a Strawsonian Theme". In Agency and Answerability: Selected Essays (Oxford: Oxford University Press), 219-259.

19. Wallace, R. Jay (2011) “Dispassionate Opprobrium: On Blame and the Reactive Sentiments”. In R.J. Wallace, R. Kumar, and S. Freeman (eds.), Reasons and Recognition: Essays on the Philosophy of T.M. Scanlon (Oxford: Oxford University Press), 348-369.

20. Wallace, R. Jay (1994) Responsibility and the Moral Sentiments. Cambridge: Harvard University Press. 